\title{
PHENOLIC GLYCOLIPID I OF MYCOBACTERIUM LEPRAE- ANTIBODY LEVELS IN HOUSEHOLD CONTACTS OF LEPROSY PATIENTS
}

\author{
S. DISSANAYAKE \\ Department of Biocbemistry, Faculty of Medicine, University of Peradeniya, \\ Peradeniya, Sri Lanka.
}

(Date of receipt : 20.06.86)

(Date of acceptance : 08.08.86)

\begin{abstract}
The levels of serum antibody to Mycobacterium leprae specific phenolic glycolipid antigen PG1 were determined in 483 leprosy patients and 1403 of their household contacts in a 5 year followup programme. Thirteen percent of the household contacts were seropositive and $3.4 \%$ had very high levels of antibodies. Household contact seropositivity was not related to the index patients antibody titre or the disease type. The determination of PG1 antibody is useful in the study of factors affecting leprosy transmission.
\end{abstract}

\section{Introduction}

Leprosy is a chronic granulomatous infection in man caused by Mycobacterium leprae. Clinical leprosy presents a wide spectrum ranging from paucibacillary tuberculoid to multibacillary lepromatous disease. ${ }^{12}$

Most attempts to use serum antibody levels as a correlate of infection with Mycobacterium leprae have been disappointing due to non-availability of antigens specific for leprosy bacillus. $1,7,10,11, P_{3}$ A phenolic glycolipid (PG1) isolated from armadillo-derived $M_{.}$leprae and characterized 8,9 has been shown to be $M$. leprae specific. ${ }^{8,9,15}$ The specific antigenic determinant on PG1 is the terminal 3,6-di-O-methyl glucose residue. ${ }^{6,15}$ An ELISA procedure developed to measure human serum antibodies to this $\mathrm{PG}^{14}$ permitted investigation of potential correlations between anti PG1-antibody and $M$. leprae infection.

We have previously reported that in patients with clinical leprosy, the levels and titres of antibody to PG1 are generally higher in multibacillary than paucibacillary patients and in treated than untreated patients. ${ }^{2,3,4,5}$ Anti-PG1 antibodies were detected in $34 \%$ of household contacts with reference to controls from Seattle, U.S.A. and in a sub-population of these contacts, the anti-PG 1 antibody was useful in predicting the development of clinical leprosy. ${ }^{3,5}$ In the present communication, we report further information on the occurrence and significance of anti-PG I antibody in household contacts of leprosy patients. 


\section{Materials and Methods}

\subsection{The study population}

The study population consisted of 483 leprosy patients and 1403 of their household contacts in Sri Lanka. The subjects were selected randomly from 12 different geographic locations and admitted to the study if they volunteered to participate in the follow up clinical examination and blood collection programme. All patients and contacts were examined by at least two clinicians with the assistance of paramedical workers of the AntiLeprosy Campaign of Sri Lanka, blood collected at least at 3-6 month intervals and followed up over a period of 5 years commencing 1980. Sufficient clinical and histological data were available to classify 304 of the 483 patients according to the Ridley Jopling classification. ${ }^{15}$ Information on household contacts was collected from the medical records and from the patients and their contacts who were seen at their home or at central clinics organised specially for this purpose.

Blood samples were collected by venupuncture, serum separated and stored at $-20^{\circ} \mathrm{C}$ in the presence of $0.01 \%$ Sodium Azide and $0.01 \%$ Thiomerzal. Control sera were collected from 118 residents of the same geographic areas who had no known exposure to leprosy patients.

The total number of household contacts with serum available was 1190. Two sera were available for 670 contacts and 3 or more sera were available for 333 contacts.

\subsection{Serum antibody to PG1}

Serum antibody to PG1 was determined by ELISA using deacylated PG1 as described previously. ${ }^{14}$ An absorbance of 0.22 at $490 \mathrm{~nm}$ wavelength (A490) in the ELISA represented more than mean +2 Standard Deviations for the 118 control sera from Sri Lanka and was considered as seropositive.

\subsection{Data analysis}

All data were stored in a Computer Database using the software package dbase II. Statistical analysis was performed by using the package SPSS adapted for Wang Professional Computer.

\section{Results}

\subsection{Serum antibody and seropositivity rates in household contacts}

In Table 1 are shown the overall seropositivity rates, mean antibody levels for serum 1 , serum 2 and serum 3 for contacts with 2 or more sera available and the correlation coefficients between follow up sera. The overall seroposi- 


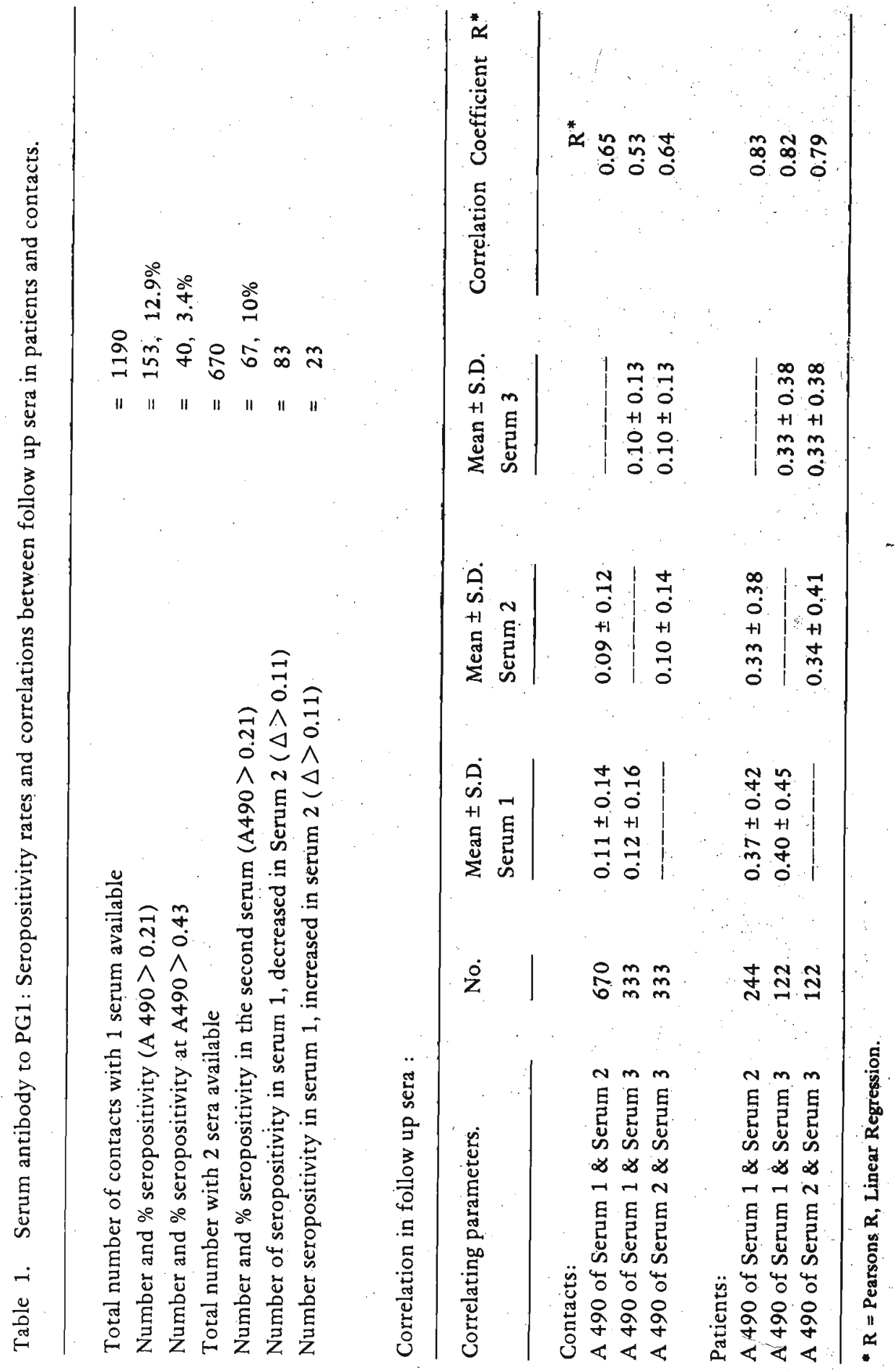


tivity rate was $13 \%$ for total contacts (A490 > $=0.22=$ Mean + 2 S.D. of Sri Lanka controls) and very high antibody levels $(\mathrm{A} 490>=0.44)$ were seen in $3.4 \%$. A total of 83 contacts showed decreasing antibody levels (change $>0.11$ ) and 23 showed increasing antibody levels (change $>0.11$ ).

In some household contacts, the serum antibody to PG1 showed considerable variation, but there was a significant correlation between the follow up sera. This correlation was of a much higher level in the case of patients than in contacts.

3.2 Correlations between antibody levels in household contacts with the antibody levels in the index patients.

In Table 2 are shown the relations observed between the index patients antibody levels and that of household contacts. The mean $\mathrm{A}_{490}$ of serum 1 and serum 2 from those contacts who had a minimum of 2 sera were used in this computation. There was approximately uniform distribution of both seronegative and seropositive household contacts in households of high, moderate and low antibody index patients.

\subsection{Correlation between contact seropositivity rates and index patient disease type.}

As shown in Table 3, household contact seropositivity was not related to the index patients disease type.

\subsection{Clustering of seropositive contacts to households.}

It was observed that the majority of seropositive contacts were restricted to certain households. Out of 213 households of family size between 2 and 6 contacts, all the seropositive contacts (total 99) were in $68(32 \%)$ households, while the remaining 145 households (total contacts 521 ) were totally seronegative. This segregation was clearer in small households (contaci size 2-3) than in large households. The seropositivity rate in the 'positive' households was $32 \%$ as compared to the overall seropositivity of $14 \%$ for this group of contacts. These results are summarised in Table 4.

3.5 Development of clinical leprosy in household contacts and relation to index patients disease type and anti-PG1 -antibody levels.

During the observation period of approximately 5 years, 13 contacts developed clinical disease. The antibody levels of both the contact and the index patient and the disease type etc, are summarised in Table 5. There was no correlation between the anti-PGl antibody levels in contacts who developed clinical leprosy and the index patients disease type or the antibody levels. 


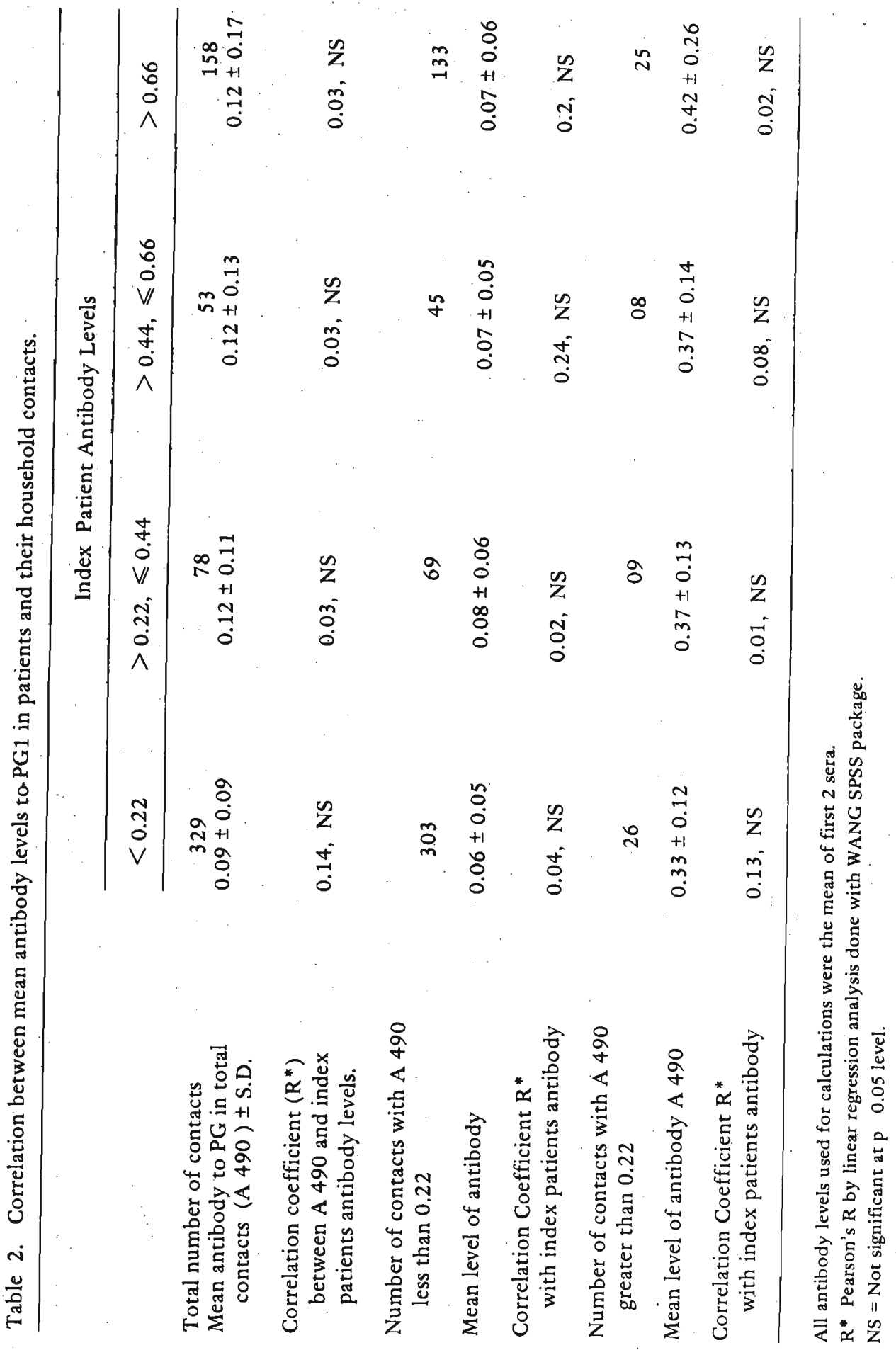




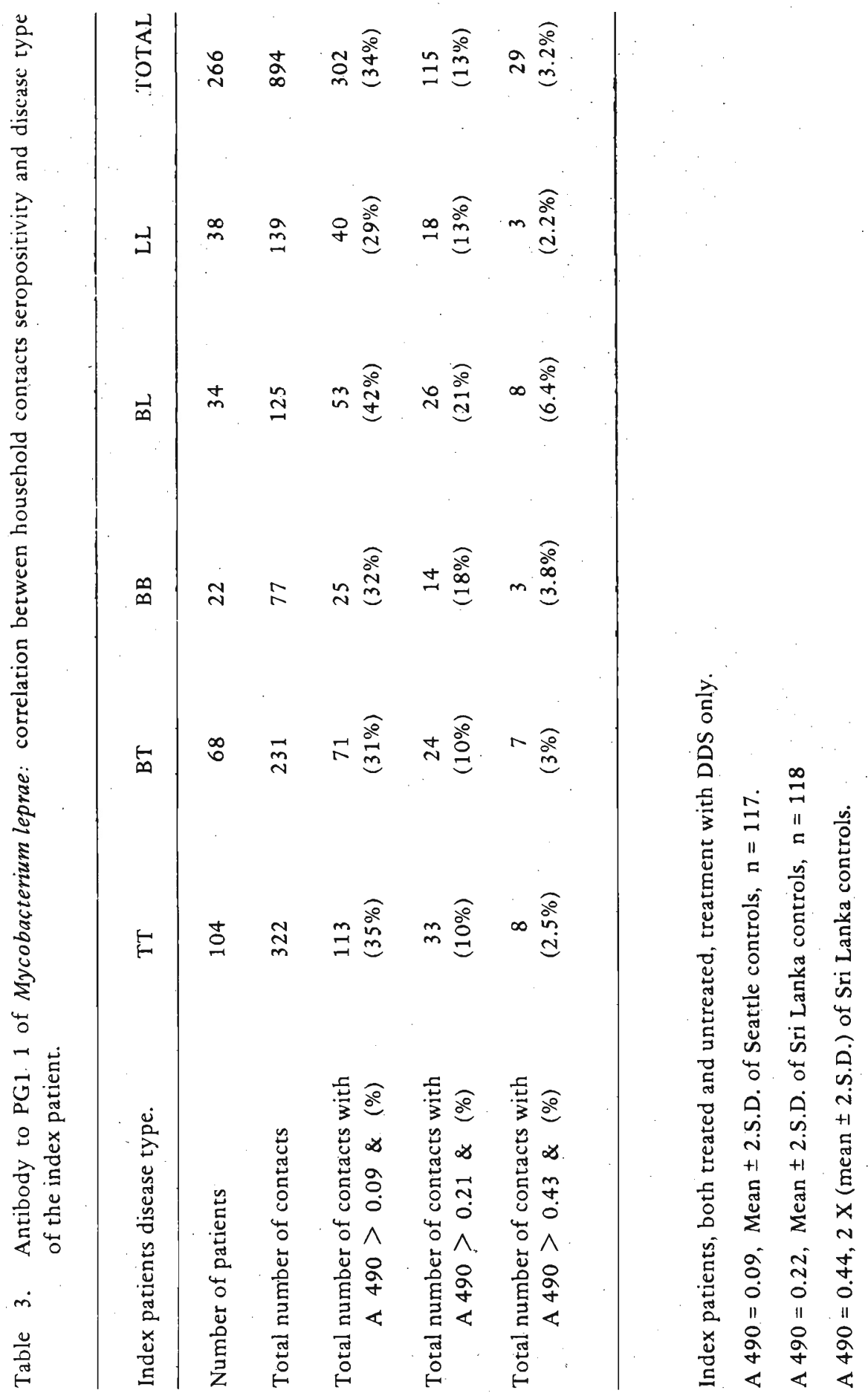




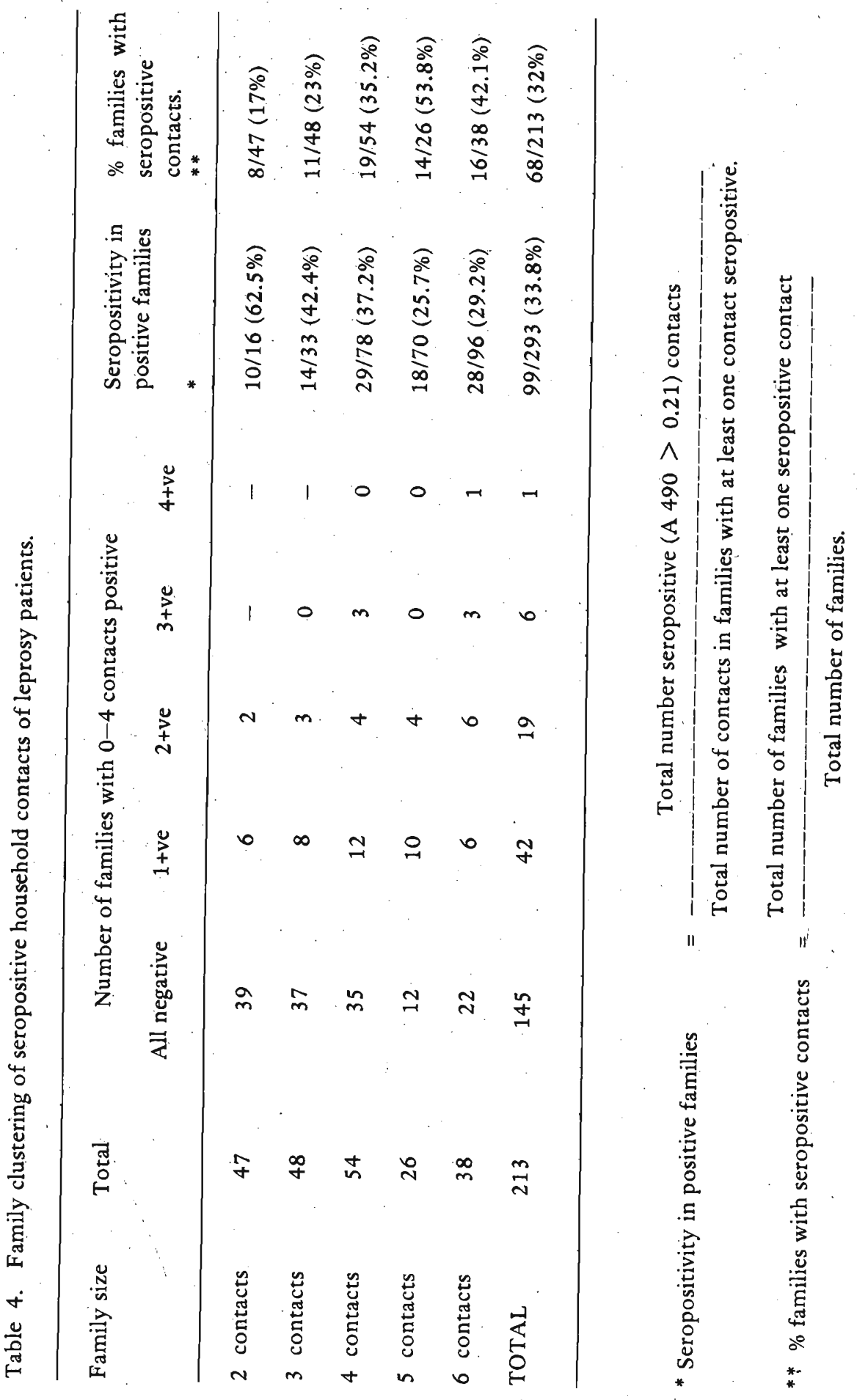




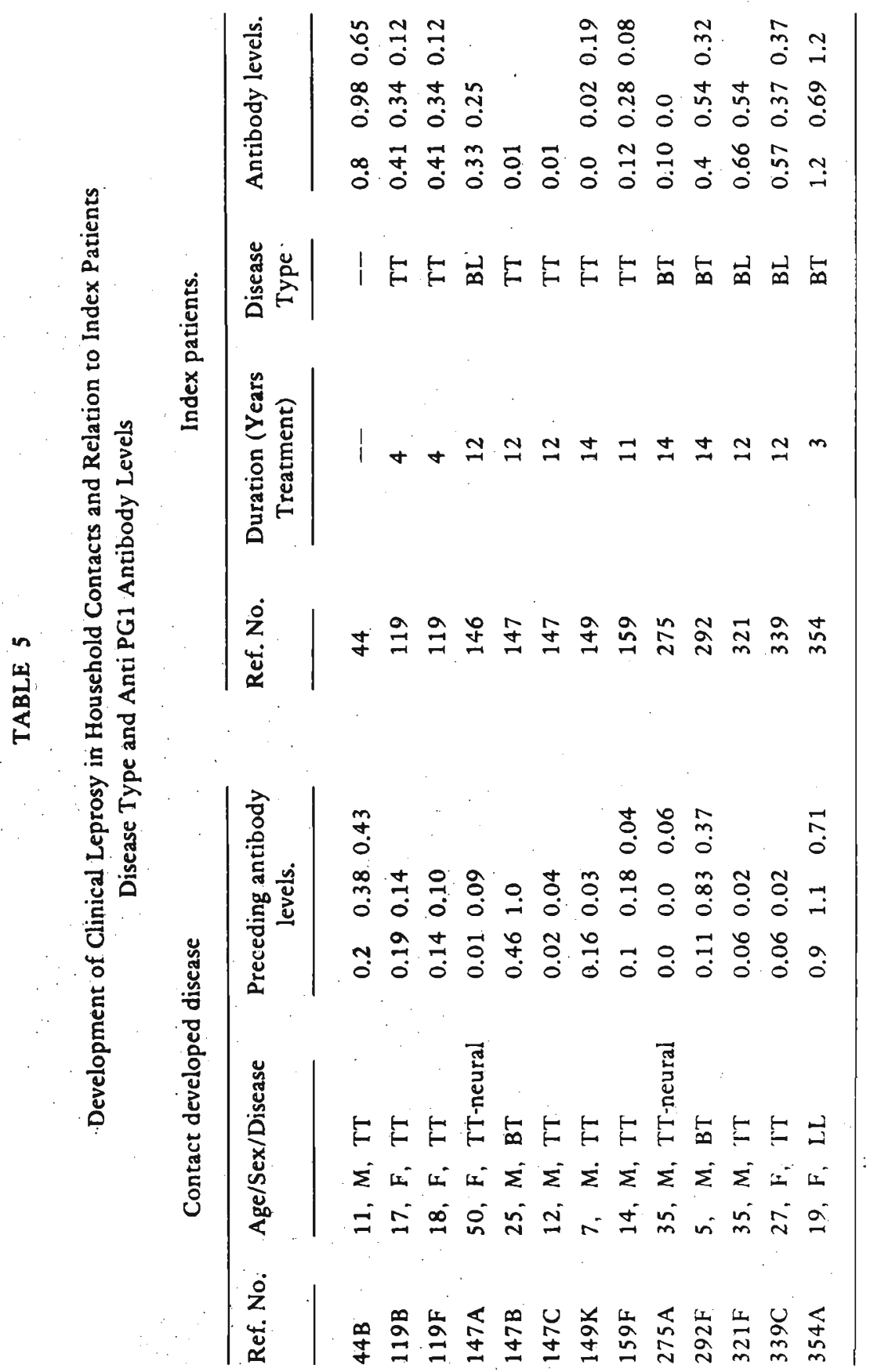




\section{Discussion}

As reported previously, ${ }^{2,3,4,5}$ the measurement of serum antibody to PG1 of $M$. leprae is useful in the diagnosis of multibacillary leprosy, in monitoring chemotherapy and in a subpopulation of infected persons, in the diagnosis of subclinical leprosy. It was also reported that household contact seropositivity was age and geographic location of residence related and could be used as a predictive criterion in the identification of contacts who are at increased risk in developing clinical leprosy. ${ }^{3}$

Data presented in the present communication show that the determination of anti-PG1 antibody in household contacts provides information that could be useful in defining patterns and epidemiological aspects of leprosy transmission. The demonstration of very high levels of anti-PG1 antibody in $3.4 \%$ of household contacts strongly implies continuous antigenic stimulation. Most importantly, if the contacts with very high levels of anti-PG1 antibody are in fact harbouring $M$. leprae, they form a hazardous reservoir of infection.

The absence of correlations between antibody levels in household contacts and the index patients type of disease and antibody levels have been reported for other antigens. $1,10,11$ The absence of such correlations between contacts who developed clinical disease and the index patient has not been reported previously. The lack of such correlations, taken together with clustering of seropositive household contacts to certain families and geographic distribution of contact seropositivity imply that environmental factors other than exposure to the patient in the family probably play a role in leprosy transmission. This could also mean that the actual source of infection is not the index patient. The development of predominantly TT/BT disease in TT/BT households was also observed. In one household, all three household contacts developed TT/BT disease over a period of approximately 10 years.

\section{Acknowledgements}

This study received support from the IMMLEP component of the UNDP/ World Bank/WHO Special Programme for Research and Training in Tropical Diseases. Excellent technical, secretarial and computer assistance of Miss S.C. Galahitiyawa is gratefully appreciated. 


\section{References}

1. ABE, M., MINAGAWA, F., YOSHINO, Y., OZAWA, T., SAIKAWA, K. \& SAITO, T. (1980) Int. J. Leprosy. $48: 109-119$.

2. BUCHANAN, T.M., DISSANAYAKE, S., YOUNG, D.B., MILLER, R.A., ACEDO, J.R., HARNISH, J.P., KHANOLKAR, S.R. \& ESTRADA PRARA, S. (1983). Int. J. Leprosy. $51: 658-659$.

3. BUCHANAN, T.M., DISSANAYAKE, S. \& ESTRADA-PRARA, S. (1985). Molecules of Mycobacterium leprae containing epitopes specific for the leprosy bacillus. Their relevance for the pathogenesis of leprosy and potential applications for serodiagnosis, skin testing, immunotherapy and vaccination. In "Symposium on Immunology of Leprosy" February 26-27, 1985. Tokyo, Japan. Sasaka Memorial Health Foundation.

4. DISSANAYAKE, S., YOUNG, D.B., KHANOLKAR, S.R., SABAPATHY, D.S.P. \& BUCHANAN, T.M. (1984) In "Proceedings of the XII International Leprosy Congress". New Delhi, India. Vol. 40.

5. DISSANAYAKE, S., GALAhITIYAWA, S.C., SABAPATHY, S.D.P. \& BUCHANAN, T.M. (1985) Proc. Sri Lanka Assn. Adv. Sci. $41: 14$.

6. FUjIWARA, T., HUNTER, S.W., CHO, S.N., ASPINALl,G.O. \& BRENAN, P.J. (1984) Infect. Immun. $43: 245-252$.

7. HARBOE, M., ClOSS, O., BJUNE, G., KRONVALL, G. \& AXELSEN, N.H. (1978) Scand. J. Immunol. $7: 111-120$.

8. HUNTER, S.W. \& BRENNAN, P.J. (1981) J. Bacteriol. $147: 728-735$.

9. HUNTER, S.W., FUJIWARA, T. \& BRENAN, P.J. (1982) J. Biol. Chem. 257 : $15072-15078$.

10. Miller, R.A., DiSSANAyAKE, S. \& BuChANAN, T.M. (1983) Am. J. Trop. Med. Hyg. 32(3) : 555-564.

11. REICH, C.V., GUINTO, R.S., CELLONA, R.V., FARRADO; T.T. \& MADARANG, M.G. (1981) Int. J. Leprosy. $49: 21-26$.

12. RIDLEY, J.S. \& JOPLING, W.H. (1966) Int. J. Lepr. $34: 255-73$.

13. YODER, Y., NAFFIS, B., HARBOE, M. \& BJUNE (1979) Lep. Rev. $50: 113-121$.

14. YOUNG, D.B. \& BUCHANAN, T.M. (1983) Science $221: 1057-1059$.

15. YOUNG, D.B., KHANOLKAR, S.R., BARG, L.L. \& BUCHANAN, T.M. (1984) Infect. Immunol. $43: 183-188$. 